\title{
Coping with the financial hardships caused by ill health - Urban Slums of Jaipur, India
}

Neha Awasthi ( $\square$ awa.neha@gmail.com )

IIHMR university https://orcid.org/0000-0002-5930-9147

Dr. Monika Chaudhary

IIHMR University https://orcid.org/0000-0002-1609-4422

\section{Research Article}

Keywords: Urban slum, Out-of-pocket Expenditure, CHE, Impoverishment, Coping Mechanism, Vulnerability

Posted Date: July 28th, 2021

DOI: https://doi.org/10.21203/rs.3.rs-754141/v1

License: (c) (1) This work is licensed under a Creative Commons Attribution 4.0 International License. Read Full License 


\section{Abstract}

Accountability of any health system does not ends with improving health. The vulnerability (to incur catastrophic health expenditure and coping mechanism) of this slum population was mostly pertaining to availability of acceptable healthcare services, accessing healthcare services and being forced to pay for it out-of-pocket. Determinant factors for vulnerability to incur catastrophic health expenditure and coping mechanism majorly included services availed.

Determinants that affected the choice of coping mechanism were availing ANC/PNC services $(\mathrm{OR}=3.8 ; \mathrm{P}<0.05)$; availed out-patients services for two or more times $(O R=2.6 ; P<0.05)$; and availed in-patients services for one or more times (including deceased members in last one year) $(O R=10.2 ; P<0.001)$. Similarly, households vulnerable to incur CHE were those which paid to avail in-patients services for one or more times $(0 R=55.3 ; p<0.001)$, childbirth services for one or more times $(O R=6.5 ; p<0.05)$ Out-patient services $(O R=11.3 ; p<0.001)$, and ANC/PNC services $(O R=6.7 ; p<0.05$. The household with more number of the households were two times more likely to incur $\mathrm{CHE}(\mathrm{OR}=2.5 ; \mathrm{p}<.0001)$.

\section{Background}

Poor health is both result and cause of poverty. The vicious circle of 'poverty leading to poor health and poor health leading to more poverty' becomes permanent in absence of adequately financed health system and/or absence of health insurance. Therefore, responsibility of a good health system does not only confide to improve health, but it extends also to ensure that people are protected from the financial consequences associated with illness and death. Protecting the welfare of the household is as important as restoring the health of an individual.

In absence of sufficiently funded public health system or public/private insurance for health, households are compelled to deploy 'coping mechanisms' for the health expenditures they incur. World Health Organization defines "To 'cope' implies much less control over a situation than to 'manage'. Coping strategies or mechanisms are remedial actions undertaken by people whose survival and livelihood are compromised or threatened." "The term 'coping strategy' was first coined during 1980s. The term refers to the mechanisms or activities undertaken by members of a household that help them survive through a crisis situation."

There is evidence that households trade off future welfare of all the members of the family to access health care for one of them, perceived as essential for survival. The future welfare may be put at risk by incurring debt, reduce consumption of essential goods selling off productive assets, or sacrificing investment in future productivity, for example by curtailing children's education. There are several determinants of coping mechanism with financial burden of seeking care. Current income and savings is used to finance the OOP expenditure, primarily by households.

Studies suggest that there can be many factors that may influence the choice of coping mechanism. Literature on coping mechanism suggests determinants such as nature of healthcare services sought; education of the head of the household; nature of employment of main income earner of the household, income level, economic status, utilization of public/private health care services, age and gender of the head of the household, demographic composition of the household, and health shocks.

Studies done globally have generated evidence that households which incurred OOP expenditure to seek in-patient care were 10 percent are likely to borrow money and/or sell assets. Households where the main income earner was employed with informal sector or were unemployed had 2.5 times higher odds of eating fewer meals than the one in the formal labor category.Utilization of private facilities increased the likelihood of selling land or other assets as the primary coping mechanism, particularly in rural areas. Likelihood of borrowing money on interest is more common in urban areas.Completion of primary education and salaried employment of household head was negatively correlated with vulnerability to health shocks but only the latter is statistically significant. Households with elderly member, chronically ill or disabled members and those having high dependency ratios are more prone to welfare loss from health shocks.

Death in the household leads to much larger reliance on relatives and friends for gifts, assistance and loans. More formal arrangements, such as borrowing from a bank, are used only sporadically.Saving is preferred by top wealth quartile groups and households with middle-aged heads. Reduction in consumption and increase in work hours may be preferred by households that lost breadwinning family member or are headed by females. Households belonging to top wealth quartile groups are least likely to borrow from formal or informal sources and sell assets.

Population burden and limited resources in less developed economies prohibit health system to provide universal coverage. Non-targeted solutions lead to excess or wasteful use of available resources and may not ensure effective coverage of vulnerable segments. To provide effective protection against financial shocks arising out of sickness, a health system must have segment specific information of determinants affecting the choice of coping mechanism or jeopardize household welfare.

Socio economic profile jaipur slums

Results

The Government of Rajasthan has announced in Budget document 21-22 that targeted interventions would be designed to protect population from health shocksThe objectives of this paper is to find determinants of catastrophic health expenditure incurred, to assess the factors influencing coping mechanism and delineate the developmental effects of catastrophic health expenditure on households of urban slums of Jaipur city.

\section{Methodology}


A conceptual framework for the study consists of identifying factors defining major aspects of vulnerability of household incurring catastrophic health expenditures. There are two major perspectives on vulnerability 1) it is a pre-existing condition and focuses on potential exposure to hazards 2 ) all individuals and groups are exposed to hazards are not equally vulnerable, rather display differential loss which depend on the coping mechanism or ability to cope.

Pre-existing condition is poverty for the population studied. Individuals or households from this population who incur catastrophic expenditures are primary units to be studied.

Note - review of methodology

Retrospective data was collected on Out-of-Pocket expenditure incurred by a household during the last 365 days prior to the survey. Data was also collected on total household expenditure incurred during the last 365 days prior to the survey including food and nonfood expenditure. The data was collected from the period of December 2017 - July 2018.

The study findings are based on data collected from 426 households from 20 urban slums of Jaipur City. The sample size was determined by taking prevalence of catastrophic health expenditure to be 15 percent, at 95 percent confidence interval with 5 percent precision andthe design effect of 2 .

Primary data was collected with the help of android based mobile application ODK. Structured schedules were used for conducting the interviews.

Based on previous studies ............dependent factors were catastrophic health expenditure and coping mechanism. Independent factors were type of services availed, composition of household, income of the household, number of earning members, type of household unit, sex of the head of the family, and literacy levelof the head of the family.

Binomial logistic regression predicts the probability that an observation falls into one of two categories of a dichotomous dependent variable based on one or more independent variables that can be either continuous or categorical. The specification of the determinants model is as follows -

\section{To determine the factors which force households to incur $\mathrm{CHE}$ following equation is used -}

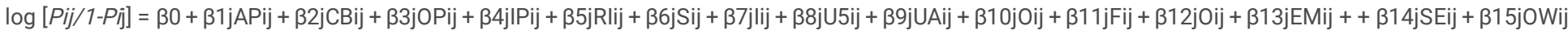
$+\beta 16 \mathrm{jH} \mathrm{lij}+\beta 17 \mathrm{jWEij}+\beta 18 \mathrm{jSAij}+\beta 19 \mathrm{jCAij}+\beta 20 \mathrm{jUNij}+\beta 20 \mathrm{jUNij}+\beta 21 \mathrm{jl} \mathrm{Lij}+\beta 22 \mathrm{jSEij}+\beta 23 \mathrm{jTEij}+\beta 24 \mathrm{j} S \mathrm{Pij}+\varepsilon 2 \mathrm{ij}$

Where the dependent variable is the log odds that household $i$ will incur $\mathrm{CHE}$, alternative $\mathrm{j}(\mathrm{j}=0)$ relative to alternative 1 , where alternative 1 is incurred $\mathrm{CHE}, 0$ is not incurred $\mathrm{CHE}$. The alternate 1 is taken as the baseline category or the reference category.

For this study, Binomial logistic regression was conducted to determine factors that force a household to incur catastrophic health expenditure and factors that compel a household to cope with health expenditure with borrowings and/or by selling assets. reason

In the above model, $M$ is the number of males in the family, AP is ANC/PNC services availed, CB is childbirth services Availed, OP is out-patient services availed, IP is in-patient services availed (present or deceased member), $\mathrm{R}$ is household possess ration card, $\mathrm{S}$ is size of the household, I is income of the household, U5 is number of under 5 years children in family, UA is the number of unmarried adolescents in family, $\mathrm{O}$ is the number of old in the family, $\mathrm{F}$ is married reproductive females in the Family, EM is the number of earning members in the family, SE is sex of head of the family, OW is household lives in owned unit, $\mathrm{HI}$ is household lives in hired unit, WE is head of the household work in household enterprise, SA is head of the household regularly salaried/pensioner, CA is head of the household work as casual worker, UN is head of the household presently unemployed, IL is head of the household illiterate, SE is head of the household educated secondary or above, TE is household is temporary structure, and SP is household is semi permanent structure.

The $\beta$ s vary by type of alternative and represent the net effects of the independent variables on the probabilities of choosing the coping mechanism. The term $\varepsilon 2$ represents unobserved determinants of coping mechanism choice and is assumed to be independently distributed.

\section{Factors forcing households to incur CHE}

Coping mechanism refers to choices to fund the healthcare expenditure. To identify the factors that determine the choices of a coping mechanism following equation is used -

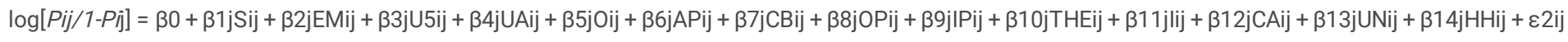

Where the dependent variable is the log odds that household $i$ will choose coping mechanism alternative $j(j=1)$ relative to alternative 2 for the health expenditure, where alternative 2 is a loan or borrowed money or selling assets, 1 is either current income, or savings or aid from relatives. The alternate 2 is taken as the baseline category or the reference category because it is with the smallest frequency.

In the above model, $\mathrm{S}$ is size of the family, EM is the number of earning members in the family, U5 is number of under 5 year children in family, UA is number of unmarried adolescents, $O$ is the number of old in the Family, AP is ANC/PNC health services availed, CB is childbirth services availed, OP is out-patient services availed, IP is in-patient services availed (including deceased members), THE is total health expenditure, I is family income, CA is head of the households casual worker compared to head of the household salaried, UN is head of the households unemployed compared to head of the household casual worker, and $\mathrm{HH}$ is head of the households work in household enterprise compared to head of the household salaried.

The $\beta$ s vary by type of alternative and represent the net effects of the independent variables on the probabilities of choosing the coping mechanism. The term $\varepsilon 2$ represents unobserved determinants of coping mechanism choice and is assumed to be independently distributed. 


\section{Findings}

\section{Determinant factors of incurring Catastrophic Health Expenditure}

Model summary of the simple binomial logistic regression is given in Table -1 . The diagnostic statistics of the model suggest that, the final model is better than the initial intercept-only model at $p=.0001(p<0.001)$, Hosmer and Lemeshow test statistic in the goodness-of-fit indicates that the model fits the data well at $p=0.861$ (which is $p>0.05$ ). Pseudo $R^{2}$ of the logistic regression is similar to ordinary least-squares linear regression, which is the proportion of variance that can be explained by the model. Nagelkerke $\mathrm{R}^{2}$, at 0.468 and Cox and Snell at 0.200 suggest that factors under consideration considerably influence the vulnerability to incur catastrophic health expenditure. Reason

Table 1

- Model fitting information for Vulnerability to Incur Catastrophic Health Expenditure

\begin{tabular}{|llll|}
\hline Model & \multicolumn{3}{l|}{ Likelihood Ratio Tests } \\
\hline Step & Chi-square & df & Sig. \\
\hline Block & 94.984 & 23 & .000 \\
\hline Model & 94.984 & 23 & .000 \\
\hline Goodness-of-Fit & 94.984 & 23 & .000 \\
\hline & & & \\
\hline Hosmer and Lemeshow Test & 3.960 & 8 & .861 \\
\hline Pseudo R-Square & Chi-square & df & Sig. \\
\hline Cox and Snell & & & \\
\hline Nagelkerke & & .200 & .468 \\
\hline
\end{tabular}

Independent variables exhibiting significant influence on likelihood of a household to incur catastrophic health expenditure. Six variables were found to be statistically significant, and out of those, four variables were related to access to healthcare services. Table -

Household characteristics such as size of the households and education of the head of the household influencedthe probability to incur catastrophic health expenditure. Likelihood $(O R=2.5, p<0.001)$ of incurring catastrophic health expenditure increased with increasing members in the household. Households with educated(Secondary or above) head of the householdwere more likely $(\mathrm{OR}=3.6, \mathrm{p}<0.10)$ to incur $\mathrm{CHE}$.

Vulnerability to incur CHE was six times if the household had utilized the healthcare services either for ANC/PNC or for child birth care at significance level $p<$ 0.05 and $p<0.10$ respectively. Odds of incurring CHE were as high as ten and fifty times, had any of the family member utilized out-patient or in-patient services at significance level $p<0.001$. Higher probability to incur catastrophic healthcare expenditure, in case OP services and IP services was due to reliance on private healthcare facility. In case of out-patient 68 percent of the household reported to utilize private health care services (includes private healthcare services utilized exclusively and mixed services from both private and public healthcare facilities) and for in-patient it was nearly 87 percent.

The families residing in kuccha (temporary structure) and semi pucca (semi permanent structure) houses were less likely to incur catastrophic health expenditure OR 0.278 and 0.317 respectively at significance level $p<0.10$. This is may be because of their lower capacity to pay. 
Table 2

- Determinants of Vulnerability to Incur Catastrophic Health Expenditure

\begin{tabular}{|c|c|c|c|c|c|c|c|}
\hline S. No. & \multicolumn{2}{|l|}{ Variables } & B & Wald & df & Sig. & $\operatorname{Exp}(B)$ \\
\hline 1. & \multicolumn{2}{|l|}{ ANC/PNC services availed } & 1.905 & 4.516 & 1 & .034 & 6.718 \\
\hline 2. & \multicolumn{2}{|l|}{ Childbirth services availed } & 1.870 & 3.734 & 1 & .053 & 6.488 \\
\hline 3. & \multicolumn{2}{|l|}{ Out-patient services availed } & 2.426 & 12.165 & 1 & .000 & 11.313 \\
\hline 4. & \multicolumn{2}{|c|}{ In-patient services availed (present or deceased member) } & 4.014 & 33.014 & 1 & .000 & 55.385 \\
\hline 5. & \multicolumn{2}{|l|}{ Household Possess Ration Card } & 1.119 & 1.715 & 1 & .190 & 3.061 \\
\hline 6. & \multicolumn{2}{|l|}{ Size of the household } & .923 & 15.996 & 1 & .000 & 2.518 \\
\hline 7. & \multicolumn{2}{|l|}{ Income of the household } & .000 & 2.389 & 1 & .122 & 1.000 \\
\hline 8. & \multicolumn{2}{|l|}{ Under 5 year in the Family } & .764 & 1.520 & 1 & .218 & 2.148 \\
\hline 9. & \multicolumn{2}{|l|}{ Adolescents in the Family } & .891 & 1.794 & 1 & .180 & 2.438 \\
\hline 10. & \multicolumn{2}{|l|}{ Old in Family } & -30.934 & .000 & 1 & 1.000 & .000 \\
\hline 11. & \multicolumn{2}{|l|}{ Married Reproductive Females in the Family } & -1.364 & 2.823 & 1 & .103 & .256 \\
\hline 12. & \multicolumn{2}{|l|}{ No. of earning members in the Family } & -1.373 & 2.508 & 1 & .113 & .253 \\
\hline 13. & \multicolumn{2}{|l|}{ Sex of the Head of the family } & .811 & .474 & 1 & .491 & 2.250 \\
\hline 14. & \multirow[t]{2}{*}{ Household Unit } & Owned & 2.788 & .000 & 1 & 1.000 & 8.303 \\
\hline 15. & & Hired & 1.763 & .000 & 1 & 1.000 & 4.094 \\
\hline 16. & \multirow[t]{4}{*}{ Occupation of Head of the Households } & Work in Household Enterprise & -1.525 & 1.140 & 1 & .286 & .218 \\
\hline 17. & & Regularly Salaried/Pensioner & -1.004 & .453 & 1 & .501 & .366 \\
\hline 18. & & Work as Casual Worker & -2.153 & 2.171 & 1 & .141 & .116 \\
\hline 19. & & Presently unemployed & -.581 & .167 & 1 & .683 & .559 \\
\hline 20. & \multirow{2}{*}{$\begin{array}{l}\text { Education of Head of the } \\
\text { Households }\end{array}$} & Illiterate & .716 & .611 & 1 & .434 & 2.046 \\
\hline 21. & & Secondary & 1.282 & 2.770 & 1 & .096 & 3.603 \\
\hline 22. & \multirow[t]{2}{*}{ Type of Household } & Kuccha (Temporary Structure) & -1.280 & 3.476 & 1 & .062 & .278 \\
\hline 23. & & Semi Pucca ( Semi Permanent Structure) & -1.148 & 3.182 & 1 & .074 & .317 \\
\hline & \multicolumn{2}{|l|}{ Constant } & -34.820 & .000 & 1 & 1.000 & .000 \\
\hline
\end{tabular}

Meeting Catastrophic Expenditure and its developmental effects on households

The pattern of expenditure clearly indicates (Table - 3) that the expenditure on food was the major part of total household expenditure among urban slum households. It is noticeable that expenditure on food is compromised with the increased level in expenditure on health. It was found that there was significant association $F=6.181(D F=5, n=426)$ at $P$-value $<.0001$ between curtailment of expenditure on food due to increment in expenditure incurred on availing healthcare services.

Table 3

- Change in distribution of total household expenditure with increasing expenditure on health

\begin{tabular}{|c|c|c|c|c|c|c|c|}
\hline \multirow[t]{2}{*}{ Health Expenditure as \% of Total Household Expenditure } & \multicolumn{7}{|c|}{ Average distribution of Total Household Expenditure (In Percent) } \\
\hline & Food & Energy & Clothing & Footwear & Education & Durable & Misc goods and Services \\
\hline No exp. on health & 69.21 & 6.67 & 2.47 & .71 & .31 & 4.44 & 16.18 \\
\hline $.001-10$ Percent & 69.19 & 6.08 & 1.60 & .29 & .51 & 3.61 & 15.96 \\
\hline 10-20 Percent & 61.31 & 6.20 & 1.77 & .40 & .12 & 1.80 & 14.90 \\
\hline 20-30 Percent & 52.44 & 7.20 & 3.04 & .50 & .01 & 2.10 & 8.83 \\
\hline 30-40 Percent & 50.30 & 5.75 & 2.83 & .75 & .53 & .76 & 8.20 \\
\hline > 40 Percent & 38.90 & 2.67 & 1.19 & .04 & .04 & 1.25 & 3.16 \\
\hline
\end{tabular}

Urban slum households live in vulnerable conditions; the same is reflected in the expenditure pattern where expenditure other than food is negligible. Expenditure on other items such as clothing, footwear, education, and durables are least when expenditure on health exceeds the threshold level of 40 percent of total household expenditure. Association between increment in health expenditure and curtailment in expenditure on food and clothing is significant $\mathrm{p}<$ 0.0001 and $p<0.05$ ( $n=426 ; f$ value $=6.181$ and 2.35 respectively). 
If catastrophic expenditures of the households in lower quintiles are mitigated, then they will be in a better position to spend on essential commodities like food and clothing. Better nutrition gives better health, and resultantly better production capacity. The vicious cycle of poverty can be broken when funds released from health expenditures are spent on food.

Coping with the financial hardships

As given in Fig. 1, most of the urban slum households funded the cost of healthcare services availed by using savings. The second choice of funding was cutting down the other household expenditure. Cost of Outpatient and Inpatient services were met through multiple sources. Incidences of selling of ornaments or other physical asset were seen in seeking outpatient and inpatient care. Borrowing was though less preferred but was prevalent in seeking all type of services.

\section{Determinants of Coping Mechanism}

The model summary of the binomial logistic regression model is depicted in Table -4 . It is clear from the diagnostic statistics of the model that, the final model is better than the initial intercept-only model at $p=.000(p<0.001)$. The Hosmer and Lemeshow test chi-square statistic in the goodness-of-fit indicates that the model fits the data well at $p=0.875$ (which is $p>0.05$ ).

Table 4

Model fitting information for determinants of coping mechanism

\begin{tabular}{|llll|}
\hline Model Fitting Information & & & \\
\hline Model & \multicolumn{4}{l|}{ Likelihood Ratio Tests } \\
\hline Step & Chi-square & df & Sig. \\
\hline Block & 54.324 & 14 & .000 \\
\hline Model & 54.324 & 14 & .000 \\
\hline Goodness-of-Fit & 54.324 & 14 & .000 \\
\hline & & & \\
\hline Hosmer and Lemeshow Test & 3.798 & 8 & .875 \\
\hline Pseudo R-Square & & & \\
\hline Cox and Snell & & & \\
\hline Nagelkerke & & 0.254 \\
\hline
\end{tabular}

In binomial logistic regression pseudo $\mathrm{R}^{2}$ is also considered. This pseudo $\mathrm{R}^{2}$ of the binomial logistic regression is similar to ordinary least-squares linear regression, which is the proportion of variance that can be explained by the model. The pseudo $R^{2}$ value between 0.20 to 0.40 is considerable in social researches. The result as given in table 15, is Cox and Snell R2 0.254 and Nagelkerke $R^{2}$ is 0.399 .

Thus, the binomial logistic regression model is reasonably good fit for estimating the determinants of coping mechanisms for OOP expenditure on Health (Table 4). The results depict the effects of independent variables on the probability of choosing coping with health expenditure either by cutting down other expenditure, savings, or aids from friends and relatives or by borrowing money or selling assets. 
Table 5

Determinants of Coping Mechanism

\begin{tabular}{|c|c|c|c|c|c|c|}
\hline \multicolumn{2}{|l|}{ Particulars } & B & S.E. & Wald & Sig. & $\operatorname{Exp}(B)$ \\
\hline \multicolumn{2}{|l|}{ Size of the Household } & .033 & .309 & .011 & .916 & 1.033 \\
\hline \multicolumn{2}{|l|}{ No. of Earning members in the family } & 1.184 & .742 & 2.550 & .110 & 3.268 \\
\hline \multicolumn{2}{|l|}{ No. of under 5 years children in family } & .060 & .483 & .016 & .900 & 1.062 \\
\hline \multicolumn{2}{|l|}{ No. of Adolescents in the Family } & .138 & .457 & .092 & .762 & 1.148 \\
\hline \multicolumn{2}{|l|}{ No. of Old persons in the Family } & -.537 & .789 & .463 & .496 & .585 \\
\hline \multicolumn{2}{|l|}{ ANC/PNC Service availed in last one year } & 1.331 & .571 & 5.437 & .020 & 3.783 \\
\hline \multicolumn{2}{|l|}{ Child birth services availed in last one year } & .212 & .801 & .070 & .792 & 1.236 \\
\hline \multicolumn{2}{|l|}{ Outpatients Services availed in last one year } & .976 & .482 & 4.100 & .043 & 2.653 \\
\hline \multicolumn{2}{|c|}{ Inpatient Services availed in last year (including deceased members) } & 2.328 & .671 & 12.053 & .001 & 10.261 \\
\hline \multicolumn{2}{|l|}{ Total Health Expenditure } & .000 & .000 & 3.265 & .071 & 1.000 \\
\hline \multicolumn{2}{|l|}{ Income of the household } & .000 & .000 & 3.992 & .046 & 1.000 \\
\hline \multirow[t]{3}{*}{ Occupation of the head of the households } & Casual workers V/S Salaried & -1.515 & .381 & 15.830 & .000 & .220 \\
\hline & Unemployed workers V/S Casual worker & -.218 & .373 & .342 & .559 & .804 \\
\hline & Work in Household Enterprise V/S Salaried & .559 & .381 & 2.151 & .142 & 1.749 \\
\hline \multicolumn{2}{|l|}{ Constant } & -2.999 & .930 & 10.390 & .001 & .050 \\
\hline
\end{tabular}

It is shown in Table 5 that those households which had to pay for availing healthcare services were most likely to opt for borrowing or selling of assets except for childbirth care services. Utilization of public healthcare facilities was highest for childbirth care services, 50 percent (Table - 5) as compared to other services. Also, many riders free Government Programs, JSSK, JSY for promoting institutional deliveries and reducing the cost of the delivery can be the possible reason for not requiring coping mechanism.

Probability to opting for coping mechanism (borrowing) was ten times if any of the household member had to get admitted in the hospital ( $P<0.05)$. The chances for opting for the coping mechanism were nearly four times and two and a half times when the household availed in-patient and out-patient services respectively. In households where the head was working as casual worker were less likely $(O R=0.22, P<.001)$.

\section{Discussion}

The urban slums of Jaipur seem to have overcome many of the problems which prevail in other slum areas, such as prevalence of larger families. Nearly, 90 percents households in Jaipur slums had four or less family members, dependency ratio (391 per 1000) which is much lower than National average 652 (Census 2011), old dependency ratio being exceptionally low. Nearly, 65 percent households are owned, and almost 90 percent households had at least one earning member in the family. Poverty ratio in urban slums of Jaipur was 2 percent.

However, it was difficult to ascertain that lower poverty ratio was either due to higher disposable income or due to higher cost of living of the city leaving no choice other than spending more saving less. As per a report on 'Government Led Exclusion of Urban Poor Greater Contribution and Lesser Recipient' by PRIA "average monthly income of urban slums of Jaipur in all the forms of employment is very less than the all India average whereas the spending pattern across the lowest and the highest-earning groups is very much higher than the all India average."

The findings of this study suggest that the health services seeking behavior was definitely a cause of vulnerability amongst urban poor. The vulnerability of this slum population was pertaining to accessing healthcare services and being forced to pay for it out of pocket. The term 'vulnerability' here is defined as a chance to incur $\mathrm{CHE}$ and probability to opt for borrowing or selling the asset as a coping mechanism.

Previous studies suggest that probability of incurring CHE and opting coping strategies depend upon type of illness, type of health care services sought (OP, IP, ANC/PNC, or childbirth), deceased member in recent past, head of the household (gender/size/education/Education etc), family income, composition of the households, economic quintile, no. of elderly members, children in the family and others."mm!

But, findings of our study suggest that no factor other than healthcare service seeking (i.e. Inpatient services, childbirth care services and deceased member of recent past having availed healthcare services in last one year) lead urban slum households to incur CHE. Likewise, opting for coping with financial shock due to ill health either by borrowing or selling assets was common amongst such households only. IPD being one of the most important factors for CE.

On the contrary, coping with current income and saving was significantly common among those household where either expenditure was between $10-20$ percent of non-subsistence household expenditure or head of the household was in regularly salaried Education.

Expenditure on 'food' constituted a major part of total expenditure. Expenditure on 'clothing', 'footwear', and 'education' all together, does not even constitute $5 \%$ of total expenditure. Their socioeconomic status is such that increased expenditure on any other item, forced them to cut down expenditure on food. 
Financing health expenditure, thus leads not only to impoverishment, but also makes them vulnerable. Thus, they fall into a vicious circle of poverty. A trap, in which poverty causes poor health and resultantly, poor health causes poverty.

\section{Conclusion}

The above findings of the study indicates that the urban slum of Jaipur city can, not only be saved from the trap of the poverty but their economic status may also be uplifted, provided they do not have to pay for the healthcare services. Presently, Healthcare System in Rajasthan is dwelling between assurance based and insurance based healthcare coverage. Resulting in, offering healthcare services to public in mixed approach. Assurance based healthcare services are offered under National Urban Health Mission where Primary Healthcare Centers are established near urban slums, free drug distribution and free investigations at all Govt. healthcare facility. State sponsored Insurance based scheme is covered under PMJAY - Ayushman Bharat.

Despite the mixed approach, neither effective universal coverage nor protection of vulnerable group against ill-health is that evident in this study. The probable reason for the same is services offered through public healthcare facilities are not accessible and/or acceptable. On other hand, State sponsored insurance scheme has limited coverage due to its riders for inclusion in the scheme. Also, poverty standards for identification of vulnerable groups are out dated and unreasonably low. Low level of poverty standard acts as a blindfold in the process of identification of actual vulnerable. This part of slum population just above poverty line on one hand remains equally susceptible to fall sick as living conditions remain same yet left out from coverage of Government led health insurance scheme. Thus, this population just above the poverty line in slum area becomes more vulnerable to incur catastrophic expenditure and to deploy coping mechanism when they pay out-of-pocket to seek healthcare services.

There are two major problems that the health system of Rajasthan is facing. Firstly, identification of the section of population at risk, secondly ways to protect this identified section of the population without exposing the other section to a similar risk. Insurance based approach for UHC, on one hand, will allow poor people to get access to expensive private healthcare. On the other hand, the increased demand for private care will raise its cost. As a result, those who are not covered under Government or private health insurance will have to bear the increased cost of health care. In such a situation, incidence of $\mathrm{CHE}$ will shift from poor households to non-poor households but it will not be reduced.

The assurance (healthcare services by public healthcare facilities) approach may not only improve the accessibility but also will control the cost of healthcare for the entire population. In place of putting two parallel systems insurance or assurance, the Government should focus to invest funds and efforts in one system. It will ensure that public finance remain in the public system. To strengthen the assurance of public health care 'Right based approach to Health' may be adopted. This will result in long term protection of its citizens.

\section{Declaration}

For this study ethical approval was granted by the ethical committee of IIHMR University. Competing interests: The authors declare no competing interests. It part of authors' phd work.

\section{References}

1. Wagstaff A. (2008), Measuring Financial Protection in Health; The World Bank Group; Policy Research Working Paper 4554

2. http://apps.who.int/disasters/repo/5517.pdf file accessed on Sep. 9, 2018

3. Ranson MK et. al. (2012); Strategies for coping with the costs of inpatient care: a mixed methods study of urban and rural poor in Vadodara District, Gujarat, India ; Health Policy and Planning, Volume 27, Issue 4, 1 July 2012, Pages 326-338

4. Wim Van Damme et. al. (2004), Out-of-Pocket health expenditure and debt in poor househols: evidence from combodia; J Tropical Medicine and International Health, Vol. 9 No 2 PP $273-280$

5. Ensor T et. al. (1996), Access and payment for health care: the poor of Northern Vietnam; Int J Health Plann Manage. 1996 Jan-Mar;11(1):69-83

6. Margret Whitehead et. al. (2001),Equity and health sector reforms: can low-income countries escape the medical poverty trap?;The Lancet, Volume 358, ISSUE 9284, P833-836

7. Basumatary J et. al. (2018); Household's Coping Mechanisms of Out-of-Pocket Expenditure on Health Care: a Case Study of Assam, India; IOSR Journal Of Humanities And Social Science (IOSR-JHSS) Volume 23, Issue 1, Ver. 9 (January. 2018) PP 70-84

8. Leive A et. al. (2008); Coping with out-of-pocket health payments: empirical evidence from 15 African countries; Bulletin of the World Health Organization 2008;86:849-856.

9. Sowmya Dhanaraj; Economic vulnerability to health shocks and coping strategies: evidence from Andhra Pradesh, India, Health Policy and Planning, Volume 31, Issue 6, 1 July 2016, Pages 749-758, https://doi.org/10.1093/heapol/czv127

10. Djesika D. Amandah et. al. (2014); Coping Strategies among Urban Poor: Evidence from Nairobi, Kenya; online file https://doi.org/10.1371/journal.pone.0083428 accessed on Sep. 19, 2018

11. Djesika D. Amandah et. al. (2014); Coping Strategies among Urban Poor: Evidence from Nairobi, Kenya; online file https://doi.org/10.1371/journal.pone.0083428 accessed on Sep. 19, 2018

12. Sowmya Dhanaraj; Economic vulnerability to health shocks and coping strategies: evidence from Andhra Pradesh, India, Health Policy and Planning, Volume 31, Issue 6, 1 July 2016, Pages 749-758, https://doi.org/10.1093/heapol/czv127

13. Ranson MK et. al. (2012); Strategies for coping with the costs of inpatient care: a mixed methods study of urban and rural poor in Vadodara District, Gujarat, India ; Health Policy and Planning, Volume 27, Issue 4, 1 July 2012, Pages 326-338

Page $8 / 10$ 
14. Sowmya Dhanaraj; Economic vulnerability to health shocks and coping strategies: evidence from Andhra Pradesh, India, Health Policy and Planning, Volume 31, Issue 6, 1 July 2016, Pages 749-758, https://doi.org/10.1093/heapol/czv127

15. Sowmya Dhanaraj; Economic vulnerability to health shocks and coping strategies: evidence from Andhra Pradesh, India, Health Policy and Planning, Volume 31, Issue 6, 1 July 2016, Pages 749-758, https://doi.org/10.1093/heapol/czv127

16. IgnaBonfrer\& Emily Gustafsson-Wright (2017) Health shocks; coping strategies and foregone healthcare among agricultural households in Kenya; Global Public Health, 12:11, 1369-1390, DOI: 10.1080/17441692.2015.1130847

17. Leive A et. al. (2008); Coping with out-of-pocket health payments: empirical evidence from 15 African countries; Bulletin of the World Health Organization 2008;86:849-856.

18. Djesika D. Amandah et. al. (2014); Coping Strategies among Urban Poor: Evidence from Nairobi, Kenya; online file https://doi.org/10.1371/journal.pone.0083428 accessed on Sep. 19, 2018

19. Ranson MK et. al. (2012); Strategies for coping with the costs of inpatient care: a mixed methods study of urban and rural poor in Vadodara District, Gujarat, India ; Health Policy and Planning, Volume 27, Issue 4, 1 July 2012, Pages 326-338

20. Sowmya Dhanaraj; Economic vulnerability to health shocks and coping strategies: evidence from Andhra Pradesh, India, Health Policy and Planning, Volume 31, Issue 6, 1 July 2016, Pages 749-758, https://doi.org/10.1093/heapol/czv127

21. IgnaBonfrer\& Emily Gustafsson-Wright (2017) Health shocks; coping strategies and foregone healthcare among agricultural households in Kenya; Global Public Health, 12:11, 1369-1390, DOI: 10.1080/17441692.2015.1130847

22. Sowmya Dhanaraj; Economic vulnerability to health shocks and coping strategies: evidence from Andhra Pradesh, India, Health Policy and Planning, Volume 31, Issue 6, 1 July 2016, Pages 749-758, https://doi.org/10.1093/heapol/czv127

23. Sowmya Dhanaraj; Economic vulnerability to health shocks and coping strategies: evidence from Andhra Pradesh, India, Health Policy and Planning, Volume 31, Issue 6, 1 July 2016, Pages 749-758, https://doi.org/10.1093/heapol/czv127

24. Sowmya Dhanaraj; Economic vulnerability to health shocks and coping strategies: evidence from Andhra Pradesh, India, Health Policy and Planning, Volume 31, Issue 6, 1 July 2016, Pages 749-758, https://doi.org/10.1093/heapol/czv127

25. Lisa Rygle et. al., (2006), a method for constructing a social vulnerability, index: an application to hurricane storm surges in a developed country, Mitigation and Adaptation Strategies for Global Change 11: 741-764.

26. Catastrophic Health Expenditure and Poor in India: New Evidence from a Nation-wide Survey [Internet]. [cited 2019 Mar 28]. Available from: https://paa2012.princeton.edu/papers/121467

27. Sahu KS, Bharati B. Out-of-Pocket health expenditure and sources of financing for delivery, postpartum, and neonatal health in urban slums of Bhubaneswar, Odisha, India. Indian J Public Health [Internet]. Medknow Publications; 2019 [cited 2019 Mar 28];61(2):67-73. Available from: http://www.ncbi.nlm.nih.gov/pubmed/28721954

28. Government Led Exclusion of Urban Poor Greater Contribution and Lesser Recipient [Internet]. [cited 2019 Mar 10]. Available from: https://terraurban.files.wordpress.com/2014/01/jaipur-status-report.pdf

29. Igna Bonfrer \& Emily Gustafsson-Wright (2017) Health shocks; coping strategies and foregone healthcare among agricultural households in Kenya; Global Public Health, 12:11, 1369-1390, DOI: 10.1080/17441692.2015.1130847

30. Sowmya Dhanaraj; Economic vulnerability to health shocks and coping strategies: evidence from Andhra Pradesh, India, Health Policy and Planning, Volume 31, Issue 6, 1 July 2016, Pages 749-758, https://doi.org/10.1093/heapol/czv127

31. Sowmya Dhanaraj; Economic vulnerability to health shocks and coping strategies: evidence from Andhra Pradesh, India, Health Policy and Planning, Volume 31, Issue 6, 1 July 2016, Pages 749-758, https://doi.org/10.1093/heapol/czv127

32. Sowmya Dhanaraj; Economic vulnerability to health shocks and coping strategies: evidence from Andhra Pradesh, India, Health Policy and Planning, Volume 31, Issue 6, 1 July 2016, Pages 749-758, https://doi.org/10.1093/heapol/czv127

33. Analyzing the Vulnerability of Catastrophic Health Expenditure in India [Internet]. [cited 2019 Jun 30]. Available from: https://iussp.org/sites/default/files/event_call_for_papers/IUSSP_9.pdf

34. T S, LP L. Which households are at risk of catastrophic health spending: experience in Thailand after universal coverage. Health Aff [Internet]. 2009;28(3):w467-78. Available from: http://ovidsp.ovid.com/ovidweb.cgi?T=JS\&CSC=Y\&NEWS=N\&PAGE=fulltext\&D=med5\&AN=19336470

35. Mondal S, Kanjilal B, Peters DH, Lucas H. Catastrophic out-of-pocket payment for health care and its impact on households: Experience from West Bengal, India. Heal (San Fr [Internet]. 2010;20. Available from: http://www.google.co.in/url?

sa=t\&rct=j\&q=\&esrc=s\&source=web\&cd=1\&ved=0CCcQFjAA\&url=http\%3A\%2F\%2Fwww.chronicpoverty.org\%2Fuploads\%2Fpublication_files\%2Fmondal_et KNsNdwyNas0znTNATG7Tq5nSOQ

36. Paul A, Malick SC, Mondal S, Lahiri SK. Exploring the determinants of catastrophic health expenditure and socioeconomic horizontal equity in relation to it: a rural community based longitudinal study in West Bengal. Int J Community Med Public Heal [Internet]. 2018 May 22 [cited 2019 Jun 30 ];5(6):2522. Available from: http://www.ijcmph.com/index.php/ijcmph/article/view/2979

37. Pandey A, Ploubidis GB, Clarke L, Dandona L. Trends in catastrophic health expenditure in India: 1993 to 2014. Bull World Health Organ [Internet]. 2018 Jan 1 [cited 2019 Aug 9];96(1):18-28. Available from: http://www.ncbi.nlm.nih.gov/pubmed/29403097

\section{Figures}




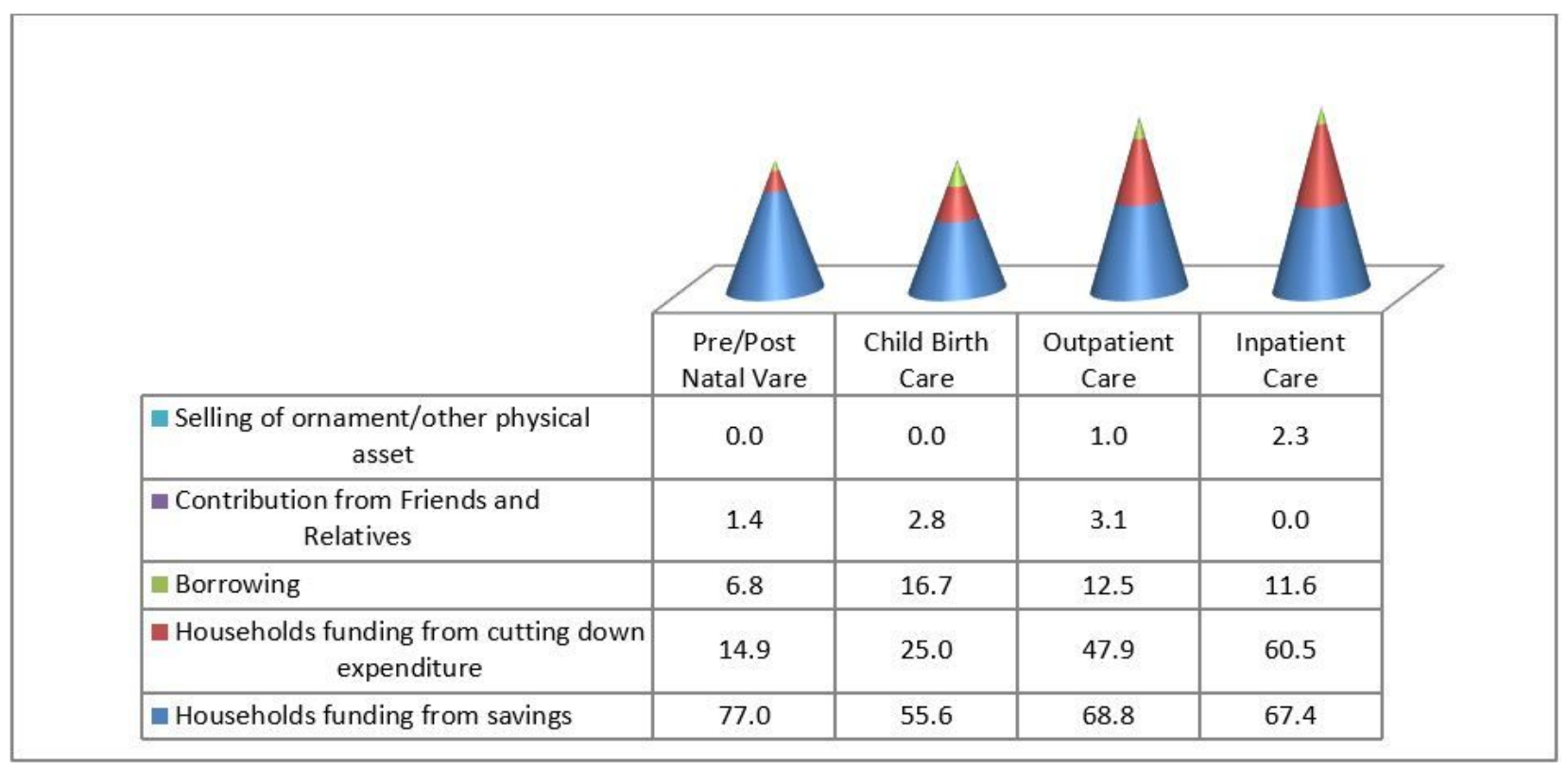

Figure 1

Coping Mechanism with financial shock depending upon the type of Healthcare Services availed (in Percent) 